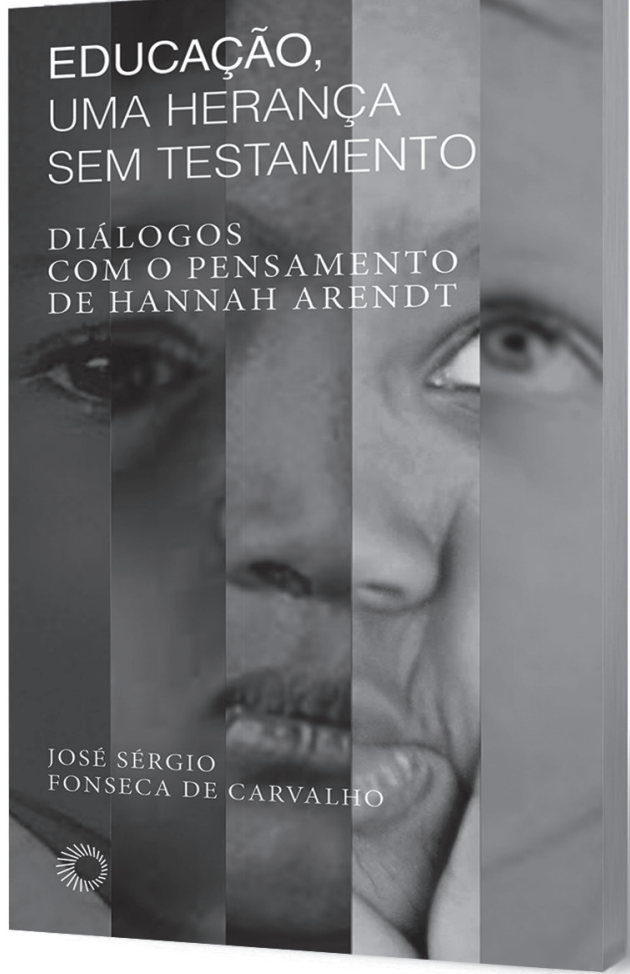

\title{
Para além de Hannah Arendt, o diálogo de José Sérgio Fonseca de Carvalho
}

\section{Carlota Boto}

Educação, uma Herança Sem Testamento: Diálogos com o Pensamento de Hannah Arendt, de José Sérgio Fonseca de Carvalho, São Paulo, Perspectiva, 2017, 144 pp. 


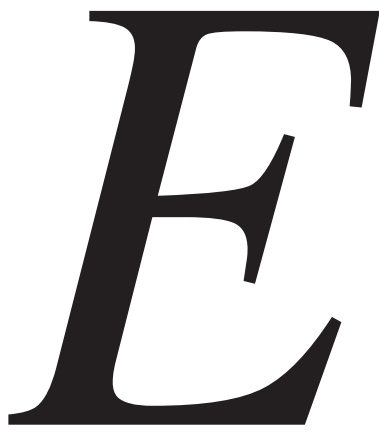

ducação, uma Herança Sem Testamento: Diálogos com o Pensamento de Hannah Arendt é o título de um importante livro para o cenário do debate pedagógico brasileiro. José Sérgio Fonseca de Carvalho lança neste ano de 2017, pela Editora Perspectiva, esse trabalho, que é muito mais do que um comentário da obra de Hannah Arendt. Trata-se efetivamente de um diálogo intelectual travado com Arendt. Um diálogo - eu diria - entre dois pensadores: Hannah Arendt, no campo da filosofia política, e José Sérgio Fonseca de Carvalho, a partir do território da filosofia da educação. O pressuposto de Carvalho é o de que a reflexão pedagógica desenvolvida por Hannah Arendt ancora-se em larga medida no que ele entende ser a "teia conceitual" de seu pensamento político. Nesse sentido, há complexidade no pensamento educacional da autora. A crise da educação, para Arendt, nada tem a ver com a obsolescência de métodos e técnicas pedagógicas. A crise na educação alicerça-se na ideia de que o ato educativo não pode prescindir nem da autoridade nem da tradição, em um mundo que perdeu as referências tanto da autoridade quanto da tradição.

Para Hannah Arendt o que há de substantivamente novo na educação é o fato de as pessoas virem ao mundo como recém-chegadas. E, chegando a este mundo comum, poderem ser habilitadas para dar continuidade a ele, por um lado, e recriá-lo, por outro lado. Assim - como diz Carvalho -, aquele que será educado é "um novo ser no mundo dos homens" (p. 3). É neste mundo preexistente que nós entramos como estrangeiros. Isso supõe a ação intencional de se fazer pertencer a uma comunidade que é histórica e é cultural, no limite, "a um mundo público” (p. 4). O livro de José

CARLOTA BOTO é professora titular de Filosofia da Educação da Faculdade de Educação da USP e autora de A Escola do Homem Novo (Editora Unesp). 
Sérgio Fonseca de Carvalho tem uma incrível unidade, tornando-se um privilegiado interlocutor do pensamento de Arendt, mas indo, em alguma medida, além das meditações dessa autora sobre o temário educacional. São cinco capítulos que abordam os vínculos entre a liberdade e a formação escolar, entre a autoridade e as distinções entre educação e política, entre o discurso de uma sociedade de consumidores e sua ressonância nas práticas educativas, entre o ideal de uma formação humanista e a vocação utilitária dos tempos que correm.

Uma das questões que José Sérgio Fonseca de Carvalho enfrenta em seu livro diz respeito às maneiras pelas quais se constitui a "formação escolar em uma sociedade de consumidores" (p. 9). Ele articula essa indagação aos anseios que parecem assolar os partidários da ideia de "modernização pedagógica". Reporta-se também à não menos entusiasmada defesa do tema da "qualidade". Essa dupla face do discurso educacional contemporâneo, que oscila entre a busca desenfreada da modernização e o intuito também obsessivo pela qualidade, oculta um aspecto fundamental daquilo que Victoria Camps chama de "virtudes públicas". Carvalho, reportando-se a essa ideia, argumenta que "compreender o declínio do sentido público da educação" (p. 10) requer a apreensão de um universo exterior ao campo educacional, posto no esfumaçamento dos limites entre os domínios do público e do privado. Essa diluição de fronteiras contribuiu para a "ascensão de uma sociedade de consumidores no mundo contemporâneo" (p. 10). Nesse sentido, em uma época em que foram privatizadas todas as esferas da vida, perde-se a dimensão de "bens públicos", ou seja, perde-se aquilo que corres- ponde ao fundo comum da cultura de um povo. Carvalho fala em "caráter público de um saber comum" (p. 12).

O livro mobiliza a análise de Hannah Arendt e, a partir dela, constrói um belo conceito que perpassa toda a análise de Carvalho: o conceito de "mundo comum". Este não se confunde com qualquer espaço coletivo. Nas palavras do autor: "[...] trata-se antes de um conjunto interligado de objetos, instrumentos, instituições, linguagens, costumes, enfim, de um mundo criado pelo artifício humano, um mundo em que adentramos ao nascer e que deixamos ao morrer" (pp. 15-6). Outra ideia fundante deste trabalho está na tese de que a vida de uma pessoa somente se transforma na existência de um "alguém" quando ocorre esse vínculo de "pertencimento ao mundo", de um mundo que é fabricado pelas mãos humanas. Assim, é no artifício da cultura que se produz o mundo humano e este conforma as pessoas, cada um como um "alguém". Em uma sociedade de consumidores, a ação política é extraída do domínio público e acaba por ser incorporada a uma ideia de gestão do social. O político que nega a política torna-se gestor privado da coisa pública. $\mathrm{O}$ discurso, portanto, da administração competente faz com que se esfacele o território da atividade política. Esta, nessa circunstância, é confundida com o âmbito do particular. Como diz Carvalho, em uma sociedade de consumidores, "esvai-se a noção de um mundo comum que transcenda a experiência individual, seja no passado ou no futuro" (p. 22). Nesse sentido, o autor considera que, quando a formação escolar está atrelada à suposta relevância econômica, ela perde de vista o próprio significado do conceito de formação, que deixa de ser intrínseco ao 
processo educativo, tornando-se exterior a ele. Quando isso acontece, "substitui-se o sentido público e político da formação por seu valor de mercado" (p. 30).

Outro aspecto importante do livro de Carvalho é a maneira pela qual ele recupera a noção de "natalidade" em Hannah Arendt. Haveria uma dupla condição quando a pessoa nasce: trata-se do surgimento de alguém novo na vida e de alguém novo no mundo. E esse conceito de alguém - como já se observou anteriormente - é central para a construção do fio condutor desta obra. Ao receber os recém-chegados à vida, partilhamos com eles uma herança, que nos foi deixada sem testamento, como nos assegura o título deste livro. Essa herança coletiva é um "legado que recebemos do passado e transmitiremos ao futuro" (p. 24). O mundo comum que ela integra é composto de tradições e interagir nesse mundo supõe a habilidade de dialogar com um acervo cultural acumulado. A educação, para José Sérgio Fonseca de Carvalho, é "um elo entre o mundo comum e público e os novos que a ele chegam pela natalidade" (p. 26). Por isso, pensar a educação, muito mais do que trabalhar as dimensões técnicas da aprendizagem, requer o reconhecimento de "experiências simbólicas". O valor formativo dessas experiências simbólicas reside no fato de que elas não constituem um aprendizado qualquer. Como diz Carvalho, "uma experiência torna-se formativa por seu caráter afetivo" (p. 27). Uma aula, um exercício, um filme ou um livro são formativos na medida em que eles nos afetam, na medida em que eles nos dizem algo relativo à nossa experiência com o mundo.

Uma particularidade importante que explica a lógica do livro situa-se na relação entre política e educação no pensamento de Hannah Arendt. Carvalho mostra que a separação radical que Arendt efetua entre esses dois domínios - educação e política - tem sido alvo de intensa crítica por parte das autointituladas teorias críticas da educação. Para Carvalho, a educação institui na vida das pessoas uma instância pré-política, já que, ao educar, estamos assumindo uma responsabilidade política pelo mundo. $\mathrm{Na}$ concepção do autor, a experiência escolar pressupõe assumir uma responsabilidade pela inserção dos alunos na "herança pública de práticas, linguagens e saberes" (p. 43) de uma comunidade que é social, e que, por isso, é também política. Para Carvalho, "essa responsabilidade é a fonte mais legítima da autoridade do educador frente aos educandos; é o que lhe confere um lugar institucional diferente daquele reservado a seus alunos" (p. 44). Haveria, sob tal enfoque, uma "assimetria de lugares" entre educador e educando, assimetria esta destinada a desaparecer no final do processo pedagógico. Para além do pensamento de Hannah Arendt, Carvalho, ao dialogar com a autora, constrói sua reflexão sobre o fato de que a relação pedagógica não é a única relação que compõe a experiência escolar. Há uma teia de interações que formam a cultura da instituição; e essa cultura escolar se expressa pela maneira como interagem os alunos entre si, os professores com os alunos, os profissionais da educação uns com os outros, etc. Há, assim, uma infinidade de experiências formativas que são processadas nas escolas. Por outro lado, ao selecionar conteúdos culturais a serem trabalhados no currículo escolar, como matéria de estudo, os educadores tomam, sim, decisões políticas ou, pelo menos, tomam 
atitudes com "potencial significação política" (p. 51).

Uma das mais interessantes reflexões que José Sérgio Fonseca de Carvalho desenvolve em seu livro situa-se na interação entre autoridade e educação. Ele parte da tese de Hannah Arendt acerca da ruptura da tradição. Com o ocaso da tradição, entra também em declínio uma forma particular de autoridade, que tem a ver com aquela na qual "o passado é concebido como modelo capaz de atribuir um significado inconteste à prática educativa” (p. 53). No âmbito pedagógico, a acepção de autoridade coincide com a pertença a um universo cultural, "que se impõe aos recém-chegados como um mundo comum que os transcende e no qual devem ser iniciados" (p. 64). Haveria, para Carvalho, portanto, um "intercâmbio intergeracional”, que dá lugar à "transmissibilidade da experiência". O passado seria a fonte de legitimação da autoridade e, na condição de referência, ilumina o presente. $\mathrm{Na}$ perspectiva de Arendt, a modernidade rejeitaria essa dimensão exemplar do passado, como fonte de legitimidade da ação educativa. Como diz Carvalho, "já não importa formar jovens dignos de seus antepassados - trata-se de prepará-los para fazer face às novidades do futuro" (p. 74). O autor critica, no limite, o "presentismo" do discurso pedagógico contemporâneo.

Ao trabalhar os vínculos entre educação e liberdade, Carvalho vale-se do pensamento de Scheffler, Passmore, Snyders e Azanha para abordar as "disputas conceituais" e o "caráter programático dos discursos educacionais" (p. 84). Reportando-se à contraposição entre a liberdade dos antigos e a liberdade dos modernos, estabelecida por Benjamin Constant, Carvalho debate a temá- tica da liberdade como prática pedagógica, interpelando o discurso das "pedagogias da autonomia". Carvalho recorda que a sociedade democrática, historicamente, não teria sido precedida pela existência de uma pedagogia democrática. Pelo contrário, a democracia na vida pública é um elemento necessário para engendrar projetos pedagógicos democráticos. Mobilizando o pensamento de Azanha, o autor observa que, "concebida como uma modalidade de prática pedagógica e identificada com procedimentos escolares, a liberdade se vê destituída de seu caráter político para se reduzir a um 'faz de conta pedagógico"” (p. 97). Diferentemente disso, a liberdade diz respeito ao "caráter aberto do futuro humano" (p. 99). Ser livre, nesse sentido, implica a possibilidade de iniciar algo irredutivelmente novo e imprevisto. Mas, para isso, a liberdade tem de ser pensada em sua acepção política, como componente intrínseco ao mundo público. Todavia, a atividade docente não se resume a transmitir um legado cultural posto no acervo historicamente acumulado. Trata-se também de formar modos de ser: atitudes. Nesse sentido, diz Carvalho: "[...] um professor revela quem ele é por seus atos e palavras; suas escolhas não se resumem a deliberações acerca de meios técnicos supostamente mais eficazes para atingir um fim, já que a forma pela qual se ensina e se aprende tem, em si mesma, um caráter formativo" (p. 105). E a forma pela qual um professor ensina tem também uma dimensão pública, que confere um sentido comum à educação ministrada.

José Sérgio Fonseca de Carvalho conclui o seu livro indagando se a experiência escolar faz ainda algum sentido. Para o autor, o sentido supremo da experiência 
escolar reside na possibilidade de conferir à iniciação dos mais novos um conjunto de "heranças simbólicas capazes de dar inteligibilidade à experiência humana" (p. 111). Por ser assim, o significado da educação escolar implica uma escolha programática. Esta vem atrelada a uma dimensão valorativa; e tem a ver com a pergunta: o que devo ensinar? O livro, nesse final, defende os princípios de uma educação humanista. Tal formação humanista permite o acesso ao legado cultural clássico e ela principalmente não prevê o aprendizado instrumental de informações e conhecimentos especializados. O objetivo, pelo contrário, é levar o indivíduo a um desenvolvimento integral, capaz de articular uma cultura comum mediante o diálogo com um acervo de saberes, de valores e de tradições historicamente acumulado. Diz Carvalho sobre o tema que "a noção de cultura geral atribui à educação um significado intrínseco: ela passa a ser um bem em si mesma independente dos possíveis - e imprevisíveis - efeitos exteriores à constituição do sujeito que se educa" (p. 113). Isso pressupõe o que o autor apresenta como uma "nova percepção do presente em sua relação com o passado" (p. 113). Aproximar-se do passado - diz Carvalho - é também definir o presente. Por essa razão, há um caráter potencialmente emancipador nesse tipo de formação, na qual a consciência se forma em relação com a obra da humanidade na história.

O livro de José Sérgio Fonseca de Carvalho, como um diálogo com a obra de Hannah Arendt, constitui um sopro de vitalidade no debate pedagógico contemporâneo. Com ideias originais e uma firme interpretação do pensamento pedagógico de Arendt, Carvalho, na matéria educacional, vai além de sua interlocutora, sem trair, entretanto, o tributo que presta a ela. Para concluir, é preciso dizer que estamos diante de um livro que se sustenta sob uma fina escrita, que, com graça e estilo, aborda temas tão complexos quanto inspiradores. Passemos, portanto, à leitura. 